\title{
Agência de Jornalismo UEPG como espaço de apoio aos movimentos sociais nos Campos Gerais do Paranái
}

\author{
UEPG Journalism Agency as a support space for \\ social movements in Campos Gerais of Paranái
}

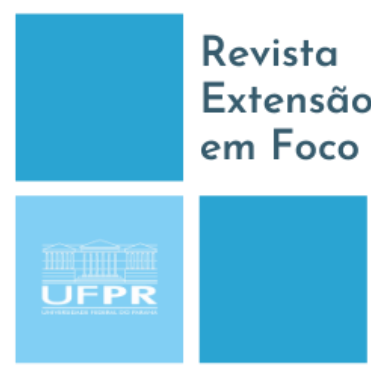

ISSN $2358-7180$

\author{
Hebe Maria Gonçalves de Oliveira ${ }^{1}$, Sergio Luiz Gadini ${ }^{2}$,
}

\begin{abstract}
RESUMO
O presente texto apresenta o trabalho realizado pela Agência de Jornalismo da UEPG, programa de extensão mantido pela Universidade Estadual de Ponta Grossa, situada na região dos Campos Gerais do Paraná. O artigo descreve algumas das atividades do Programa, que busca atender demandas de organizações sociais sem fins lucrativos que buscam apoio da Agência para produção de materiais de divulgação para suas respectivas ações junto à comunidade. Criado em 2003, A Agência atualmente mantém parceria e presta apoio - através de estudantes e docentes de Jornalismo - para entidades, associações e movimentos sociais populares de Ponta Grossa e região. Para garantir visibilidade de tais produções, a Agência de Jornalismo também mantém diálogo e interação com a Rádio Comunitária Nova Rússia (Rádio Princesa FM 89,7) e a Associação das Entidades Usuárias do Canal Comunitário (TVCom PG, canal $17 \mathrm{Net}$ cabo). As atividades desenvolvidas em parcerias proporcionam uma visibilidade de ações populares que, de modo geral, praticamente não encontram espaço e projeção junto aos meios e produtos da mídia comercial hegemônica na região e estado.
\end{abstract}

Palavras-chave: Agência de Jornalismo UEPG. Movimentos sociais. Extensão universitária em Jornalismo.

\section{ABSTRACT}

This paper presents the work done by the UEPG Journalism Agency, an extension program maintained by the Ponta Grossa State University, located in the Campos Gerais region of Paraná. The article describes some of the activities of the Program, which seeks to meet the demands of nonprofit social organizations seeking support from the Agency to produce promotional materials for their respective actions with the community. Created in 2003, the Agency currently maintains a partnership and provides support through journalism students and teachers - to entities, associations and popular social movements in Ponta Grossa and the region. To ensure visibility of such productions, the Journalism Agency also maintains dialogue and interaction with Nova Russia Community Radio (Princesa FM Radio 89.7) and the Community Channel User Association (TVCom PG, Channel 17 Net Cable). The activities developed in partnerships provide visibility of popular actions that, in general, hardly find space and projection with the hegemonic commercial media and products in the region and state.

Keywords: Journal. UEPG Journalism Agency. Social movements. University extension in Journalism.

\footnotetext{
${ }^{1}$ Universidade Estadual de Ponta Grossa (UEPG), Ponta Grossa, Paraná, Brasil. hebegoncalves@uepg.br Orcid: https://orcid.org/0000-0002-4076-9549

${ }^{2}$ Universidade Estadual de Ponta Grossa (UEPG), Ponta Grossa, Paraná, Brasil. slgadini@uepg.br Orcid: https://orcid.org/0000-0002-1537-1387
} 


\section{INTRODUÇÃO}

A Agência de Jornalismo UEPG é um programa de extensão, mantido por estudantes e professores do Curso de Jornalismo da Universidade Estadual de Ponta Grossa, na região Sul do Paraná. Criada em 2003, a Agência logo passa a interagir com diversos setores da comunidade e, aos poucos, o perfil de um espaço de apoio aos segmentos que precisam de apoio na área de comunicação passa a ser o foco de ação do programa extensionista.

O presente texto descreve algumas das atividades do Programa, que busca atender demandas de organizações sociais sem fins lucrativos que buscam apoio da Agência para produção de materiais de divulgação para suas respectivas ações junto à comunidade. As atividades desenvolvidas em parcerias proporcionam uma visibilidade de ações populares que, de modo geral, praticamente não encontram espaço e projeção junto aos meios e produtos da mídia comercial hegemônica na região e estado. Para compreender o contexto regional é oportuno discutir alguns conceitos que orientam o trabalho da extensão e, em seguida, apresentar alguns indicadores que caracterizam a região em que está localizada a UEPG.

\section{PARA ENTENDER A PRÁtICA DE EXTENSÃO UNIVERSITÁRIA NO BRASIL}

A Extensão Universitária se consolidou no Brasil como um dos eixos que sustentam a Universidade Pública, ao lado do ensino (em graduação e pós-graduação) e da pesquisa. E, assim, a extensão torna-se, gradualmente, uma das funções sociais inerentes ao modo de entender, viver e gestar a universidade pública, em uma sintonia com os problemas e dificuldades que marcam as respectivas regiões de alcance e atuação de cada instituição. Trata-se, pois, de um espaço e meio de interagir com as comunidades do entorno, que também possuem modos próprios de saber (popular), que contribuem no enriquecimento científico e na formação profissional da universidade.

Em outros termos, ao manter e interagir com os diversos atores e grupos sociais, a universidade também se legitima e possibilita que estudantes, docentes e servidores tenham acesso à práticas de produção do conhecimento secular que contribuem, reciprocamente, no respeito às iniciativas e relações que envolvem direitos humanos, 
demandas ou problemas sociais que marcam o cotidiano das respectivas comunidades, cidades ou bairros do entorno de ação das respectivas instituições (IES).

Ao planejar e propor iniciativas, seja por meio de projetos, programas, cursos e demais eventos, os agentes universitários têm em conta que a justificativa primeiro de tais ações decorre de demandas ou interesse de setores das respectivas organizações e comunidades. É uma lógica de inserção dialógica, que fortalece, respeita e legitima os mais variados modos de pensar, viver e agir dos grupos e atores sociais envolvidos nas ações extensionistas. Para a universidade, obviamente, trata-se de compreender que, acima de tudo, está em jogo um respeito ao conhecimento, que pode gerar outras práticas que auxiliam nos processos de formação e existência social da própria universidade, de forma democrática, respeitosa e humana.

\section{BREVE NOTA SOBRE A HISTÓRIA E O CONCEITO DE EXTENSÃO UNIVERSITÁRIA}

O surgimento oficial da extensão é marcado por uma série de referências na história das universidades, que indica a Inglaterra (em 1871) como um dos marcos a lançar programas institucionais, seguido por anos depois por IES de outros países, como Bélgica, Alemanha e outros países europeus (PAULA, 2013, p.6). Existem, claro, outras referências, não necessariamente datadas, que revelam iniciativas com caráter extensionista, como é o caso dos documentos da igreja católica (bases da doutrina social), na carta Rerum Novarum, do papa Leão XIII (1891).

Em levantamento histórico, o professor João De Paula, ex-pró-reitor da UFMG, também recupera uma tradição 'socialista' na prática da extensão, que teria surgido na Europa nas últimas décadas do mesmo Século XIX:

\footnotetext{
“Outra corrente a ser considerada nesse contexto é a dos 'socialistas do Estado', ou 'socialistas de cátedra', que reuniu os economistas Gustav Schmoller, Adolf Held, Lujo Brentano, Christian Engel, Adolf Wagner e outros, que fundaram, em 1873, a Sociedade para a Política Social, que contribuiu para reforçar as críticas ao capitalismo do laissezfaire ao mesmo tempo em que deu uma ajuda poderosa à política de Bismarck de implantação do seguro social obrigatório, como também à política protecionista adotada por ele em 1880 (COLE, vol. II, 1958, apud DE PAULA, 2013, p.9).
}

Esta marca 'socialista' é uma referência secular que, desde o surgimento da universidade laica, que não fica restrita ao controle de instituições católicas, aproxima intelectuais de movimentos sociais em uma relação frequente, pautada na busca de compreensão, diálogo e solução aos incontáveis problemas sociais que marcam as 
diferentes épocas e países, desde o século XVII, como se pode constatar em diversas obras autorais de pensadores que passaram ou desenvolveram pesquisas e trabalhos sociais (de extensão) em parceria, diálogo ou a partir de universidades.

$\mathrm{Na}$ América Latina, um marco referencial no surgimento da extensão universitária é o movimento pela Reforma Universitária de 1918, impulsionado pelos estudantes da Província Córdoba, na Argentina.

\begin{abstract}
"Homens de uma República livre, acabamos de romper a última cadeia que, em pleno século XX, nos atava à antiga dominação monárquica e monástica. Resolvemos chamar todas as coisas pelos nomes que têm. Córdoba se redime. A partir de hoje contamos para o país uma vergonha a menos e uma liberdade a mais. As dores que ficam são as liberdades que faltam. Acreditamos que não erramos, as ressonâncias do coração nos advertem: estamos pisando sobre uma revolução, estamos vivendo uma hora americana”. (MANIFESTO DE CÓRDOBA, 21/06/1918).
\end{abstract}

No Brasil, é oportuno lembrar que o movimento estudantil organizado, desde o surgimento das primeiras instituições de ensino superior, cobra espaço de representação e luta pela universidade pública, resultando na criação da União Nacional de Estudantes, em 11/08/1937. Não por acaso, as demandas de fortalecimento da universidade no cotidiano da vida dos brasileiros, através de ações extensionistas, podem ser associados ao que se consolidou como diretrizes ou políticas de extensão nas universidades públicas do País (UNIÃO NACIONAL DOS ESTUDANTES, S/D).

As reviravoltas e trapalhadas governistas no pré até o fim da segunda guerra deixam o Brasil também envolto em problemas socioeconômicos que não são exclusivamente nacionais, e marcam um período com impacto nas universidades até o pós-guerra, quando movimentos sociais retomam lutas pela democratização, que fortalecem ações extensionistas, até o golpe militar de 1964, que acaba com liberdades de expressão e intervém de forma autoritária no cotidiano da política e também no funcionamento das universidades. A história recente da luta em defesa da Universidade, que envolve intelectuais, estudantes e os mais variados segmentos sociais, entre 19641985, tem em Darcy Ribeiro um das referências pela redemocratização. Com o fim do regime militar (pós-1985), as universidades voltam a viver o clima de expressão, pluralidade cultural e, pois, também se ampliam as iniciativas que envolvem práticas de extensão universitária em todo o País.

\title{
BREVE PASSEIO NOS INDICADORES DOS CAMPOS GERAIS DO PARANÁ
}


Associado a uma carência regional por recursos humanos que atuam na área, a Agência passa a orientar, de forma prática, organizações, movimentos e entidades comunitárias que buscam apoio para dar visibilidade social às suas respectivas ações de interesse coletivo. As ações comunicacionais da Agência de Jornalismo para entidades e movimentos sociais parceiros consistem na produção de material jornalístico para divulgação nas redes sociais, releases para imprensa, alimentação de páginas nas redes sociais, coordenação de comunicação interna e produção jornalística audiovisual para veiculação na TV Comunitária e redes sociais, como Youtube e Facebook, coordenação e divulgação de eventos, entre outras.

A atual orientação editorial do Programa Agência considera a comunicação como área cada vez mais central e estratégica nas sociedades contemporâneas e, portanto, relevante para assegurar condições de expressão, visibilidade projeção aos mais diversos grupos e organizações coletivas. Entende-se, assim, a realidade de entidades e movimentos sociais populares, que baixa ou total ausência de recursos financeiros e profissionais especializados, para a desenvolvimento de ações comunicacionais. E, aí a reside a importância de atuação da Agência de Jornalismo, com o objetivo maior de atender a esta demanda na cidade e região.

A Agência de Jornalismo, através da parceira com a TV Comunitária, também tem o papel de possibilitar a ampliação da divulgação das ações das entidades e movimentos sociais parceiros, por se tratar de um canal com princípios diferenciados da lógica da mídia comercial e, pois, voltado essencialmente a promover ações coletivas, do bem comum, e inclusivas.

A proposta da Agência de Jornalismo de Jornalismo visa, assim, dar visibilidade às atividades das entidades, grupos e movimentos sociais populares parceiros, através de ações comunicacionais, disponibilizadas em redes sociais e TV Comunitária de Ponta Grossa (TV Com). E, da mesma forma, o Programa Agência busca promover ações comunicacionais de entidades, grupos e movimentos sociais populares parceiros de forma a proporcionar a divulgação de uma agenda positiva ausente dos convencionais veículos de comunicação.

A Agência de Jornalismo trabalha com uma metodologia que opera em sintonia com cada modo de operar e interagir na sociedade. E, assim, após uma aproximação inicial, estudantes e professores buscam conhecer o foco de ação de cada organização 
(grupo, entidade ou movimento) para, aos poucos, propor diretrizes de intervenção de mídia que melhor atendam às necessidades e, ao mesmo tempo, se possa registrar uma maior eficácia e alcance comunicacional com o respectivo público-alvo de horizonte.

Considere-se que a parceria com diversos setores sociais resulta do próprio perfil do Curso de Jornalismo da UEPG, consolidado ao longo de vários anos de ação na comunidade, com uma inserção e envolvimento em questões e demandas por políticas públicas na cidade e região. Dessa inserção e engajamento do conjunto de professores, estimulando sempre a participação dos estudantes, o Curso também tem construído uma referência local ao atendimento de demandas da comunidade que perpassam pela produção jornalística e comunicacional. E, assim, a Agência de Jornalismo tem se colocado prontamente a atender, embora com limitações materiais e acadêmicas, às atividades solicitadas por diversos parceiros.

\section{REFERÊNCIAS DE UMA INSERÇÃO EXTENSIONISTA NA COMUNIDADE}

Neste período, entre as organizações parcerias da Agência de Jornalismo da UEPG pode-se citar as comunidades regionais do Movimento dos Trabalhadores Rurais Sem Terra (MST), como Pré-Assentamento Emiliano Zapata, em Ponta Grossa, e o Acampamento Maria Rosa do Contestado, em Castro; a Sociedade Afro-brasileira Cacique Pena Branca, a Rádio Comunitária Nova Rússia (Rádio Princesa FM 89,7); A Associação das Entidades Usuárias do Canal Comunitário de PG (TVComPG Canal 17 Net cabo); Sindicato dos Professores da UEPG (Sinduepg), Rede de Mulheres Agricultoras em Agroecologia Emiliano Zapata (MST), Pastoral do Mundo do Trabalho, os coletivos Frente Popular dos Movimentos Sociais de Ponta Grossa, Frente Brasil Popular Campos Gerais, Povo Sem Medo PG, Fórum das Águas dos Campos Gerais e o Fórum em Defesa da Previdência Pública (GONÇALVES e RODRIGUES, 2017).

A Agência de Jornalismo também apoia, através da produção de materiais de divulgação (pré e pós-evento), conferências temáticas de políticas públicas locais, como I Conferência Municipal de Direitos Humanos de PG (13/02/2016), a Conferência Municipal de Cultura (nas edições de de 2015, 2016 e 2017) e a Conferência das Cidades em Ponta Grossa (13 e 14/05/2016), além de eventos pela democratização da 
mídia e debates sobre cultura, cidadania e história contemporânea, como o painel temático "Desconstruir o Golpe", evento que marcou a descomemoração do golpe militar (realizado anualmente em 31/03) na cidade.

A parceria com a Rádio Comunitária (FM 89,7) viabilizou a produção do "Democracia em Debate" - programa de entrevistas radiofônico em parceria com a Rádio Comunitária Princesa (89,7 FM), veiculado de segunda a sexta-feira, das 8 h10 às 8h30, no período de abril a setembro de 2016. A proposta do "Democracia em Debate" foi discutir o processo de impeachment da presidenta Dilma Rousseff, através das entrevistas a diferentes vozes ligadas a setores progressistas da sociedade, como professores e pesquisadores de diferentes áreas de atuação profissional e lideranças de movimentos sociais populares, com abordagem diferenciada a que marcou os meios de comunicação hegemônicos nacionais e locais.

A Agência de Jornalismo também viabilizou, entre 2011 e 2014, a coordenação mediada de um programa laboratorial de crítica de mídia e cultura ("Crítica na TV"), realizado por estudantes do segundo ano de Jornalismo da UEPG, para o Canal Comunitário, com edição semanal de 15 minutos.

O direito à informação, ainda que não paute de forma integrada e global permanente as iniciativas dos movimentos sociais, recoloca, cada vez mais, a necessidade de produção de conteúdos que atendam às demandas de organizações sem fins lucrativos, que buscam espaço para comunicar suas ações e iniciativas.

É neste contexto que, a partir de 2014, a Agência de Jornalismo UEPG passa a produzir materiais, que circulam em redes sociais e também ficam disponíveis na internet (redes, sites e canais no You Tube), em sintonia com demandas de movimentos e organizações da cidade região. E, assim, na prática, o debate sobre a descentralização e democratização da mídia na materializa, diante de demandas coletivas por produção de conteúdos, frente ao acirramento da hegemônica presença e concentração dos meios no setor privado de comunicação.

Para a comunidade Emiliano Zapata (MST), destacam as ações de comunicação para promover a Rede de Mulheres Produtoras em Agroecologia, voltada ao cultivo de alimentos livres de agrotóxicos. A Rede de Mulheres constitui-se em um grupo de camponesas integrantes do MST, que atuam na produção em agroecologia, na perspectiva da agricultura sustentável e da geração de renda para famílias de pequenas 
camponesas. Entre essas ações comunicacionais, inclui-se a manutenção semanal de contatos da Rede de Mulheres aos consumidores permanentes, através da lista de emails, além de ações de comunicação externa para atrair novos consumidores parceiros, através da produção de conteúdo (foto, texto e vídeo) para alimentação da página no Facebook, assim como a divulgação em palestras e eventos públicos, como nos espaços da Universidade, contatos com diferentes potenciais consumidores, etc. Ações desta natureza são de total importância, considerando os dados do IBGE.

O último Censo Agropecuário (2006) indicou que a agricultura familiar corresponde a $84,4 \%$ da produção agrícola no Brasil. E que o contingente de produtores familiares ocupam à área de 80,25 milhões de hectares, o que representa 24,3\% da produção agrícola no País. No contexto regional, a região Sul do País abriga 19,2\% da agricultura familiar brasileira e 16,3\% da área total da produção agrícola (FRANÇA, GROSSI, MARQUES, 2009, p.20). Outro aspecto a considerar é a própria atuação das mulheres na agricultura familiar, no papel de chefes de famílias ou na participação da renda familiar, e na agricultura agroecológica. (SILIPANDI, 2009). Nesse sentido, a importância de dar visibilidade às ações quase invisíveis das produtoras camponeses.

Quanto à produção de audiovisual, a Agência de Jornalismo tem atuado na cobertura jornalística da Jornada de Agroecologia organizada pelo MST, como ocorreu em julho 2015 e julho de 2016, com destaque para as conferências principais do evento, como a de João Pedro Stédile e do teólogo Frei Beto, em julho de 2015, e do teólogo Leoanrdo Boff, em julho de 2016. Já em 2017, a cobertura da participação das camponesas na Marcha em Ponta Grossa, no dia Mundial das Mulheres (produção audiovisual divulgada nas redes sociais e TVCom).

Outra produção audiovisual importante trata-se do documentário Doze meses de resistência: a terra como horizonte de vida, que retrata um ano de ocupação do acampamento Maria Rosa do Contestado (MST/Castro), completos em 24 de agosto de 2016. Com duração de 46 minutos, o documentário constitui-se do relato de camponeses e camponesas sobre o dia da ocupação, o cotidiano, a luta pela terra, as conquistas e o cultivo da partir da agroecologia como perspectiva de vida. $\mathrm{O}$ documentário teve um pré-lançamento em 24 de agosto de 2016, durante o evento comemorativo do aniversário de um ano do acampamento e lançamento oficial do produto final em 09 de julho de 2017. Para o lançamento final do documentário, foram 
entregues à comunidade 20 cópias em formato CD-Rom (reprodução com recursos próprios de professores envolvidos), além da disponibilização nas redes sociais. Para uso sem ônus da Canção Terra como trilha sonora do documentário Doze meses de resistência, a Agência de Jornalismo obteve autorização de direitos autorais cedida pelo cantor e compositor gaúcho Pedro Munhoz e também da Som Livre 100\% Edições Musicais.

Para a comunidade do Acampamento Maria Rosa do Contestado (MST) ainda foi realizada a cobertura jornalística da audiência pública "Agroecologia e Produção Livre de agrotóxicos", em Castro em 18 de fevereiro de 2016, conteúdo disponibilizado nas redes sociais.

Para os coletivos Frente Popular dos Movimentos Sociais de Ponta Grossa, Frente Brasil Popular Campos Gerais, Povo Sem Medo - Ponta Grossa, Fórum das Águas dos Campos Gerais e Fórum em Defesa da Previdência Social, a produção audiovisual também foi realizada em eventos, como debates, palestras e atos de rua. Para todas essas ações, inclui a alimentação de páginas nas redes sociais dos respectivos coletivos e entidades.

Dentre as ações para o Mestrado em Jornalismo destaca-se o apoio integrado ao Grupo de Estudos Jornalismo, Política e Representações Coletivas, à organização do Debate entre candidatos a prefeito de Ponta Grossa nas Eleições Municipais 2016, em 23 de agosto de 2016. Historicamente, o Curso de Jornalismo tem se colocado ativo na realização de debates em eleições municipais ou gerais, com a parceria de demais entidades. Em 2016, além da Agência de Jornalismo, o evento contou com a parceria do Sindicato dos Docentes da UEPG (Sinduepg), Centro Acadêmico de Jornalismo João do Rio (Cajor), PPG-Educação/UEPG, Sindicato dos Técnicos e Professores da UEPG (Sintespo), Austran (Associação dos Usuários de Transporte Público), Faculdades de Jornalismo Secal. À Agência de Jornalismo coube o apoio na produção técnica, como montagem de cenário, cronômetro eletrônico, divulgação de release à imprensa local, contato direto com os assessores dos candidatos e produção jornalística do próprio debate e divulgação nas redes sociais.

Entre os diversos trabalhos realizados pela Agência de Jornalismo, pode-se listar diversas ações comunicacionais (produção jornalística para TVCom e redes sociais) 
como coberturas das atividades das entidades parceiras no período de 2015 e 2018. (Tabela 1).

Tabela 1 - Atividades da Agência de Jornalismo UEPG

\begin{tabular}{|c|c|c|c|}
\hline ATIVIDADE & CONTEÚDO & PERÍODO & ENTIDADES \\
\hline $\begin{array}{l}\text { VT/TVCom e redes } \\
\text { sociais }\end{array}$ & $\begin{array}{l}\text { Projeto de lei do governador Beto Richa com } \\
\text { alterações no Fundo da ParanaPrevidência }\end{array}$ & Abril - 2015 & Sinduepg \\
\hline $\begin{array}{l}\text { VT/TVCom e redes } \\
\text { sociais }\end{array}$ & $\begin{array}{l}\text { Projeto de lei do governador na } \\
\text { ParanaPrevidência aprovado após massacre aos } \\
\text { professores, estudantes e servidores públicos } \\
\text { em } 29 \text { de abril de } 2015\end{array}$ & Maio - 2015 & Sinduepg \\
\hline $\begin{array}{l}\text { VT/TVCom e redes } \\
\text { sociais }\end{array}$ & $\begin{array}{l}\text { Retorno às aulas }- \text { fim da greve dos } \\
\text { professores } 2015\end{array}$ & Junho -2015 & Sinduepg \\
\hline $\begin{array}{l}\text { VT/TVCom e redes } \\
\text { sociais }\end{array}$ & $14^{\mathrm{a}}$ Jornada de Agroecologia, Irati & Julho -2015 & MST \\
\hline $\begin{array}{l}\text { VT/TVCom e redes } \\
\text { sociais }\end{array}$ & $\begin{array}{l}\text { Denúncia contra projeto de reclassificação da } \\
\text { bacia do Rio Tibagi }\end{array}$ & Julho/2015 & $\begin{array}{l}\text { Fórum das Águas } \\
\text { dos Campos Gerais }\end{array}$ \\
\hline $\begin{array}{l}\text { Atividades de } \\
\text { organização }\end{array}$ & $\begin{array}{l}\text { II Fórum das Águas dos Campos Gerais - } \\
\text { redes sociais }\end{array}$ & julho de 2015 & $\begin{array}{l}\text { Fórum das Águas } \\
\text { dos Campos Gerais } \\
-22 / \text { julho/2015 }\end{array}$ \\
\hline $\begin{array}{l}\text { Atividades de } \\
\text { comunicação para } \\
\text { imprensa }\end{array}$ & Acampamento Maria Rosa do Contestado & Agosto/2015 & $\begin{array}{l}\text { Pré-Assentamento } \\
\text { Maria Rosa/Castro }\end{array}$ \\
\hline $\begin{array}{l}\text { Release e divulgação } \\
\text { em redes socais }\end{array}$ & $\begin{array}{l}\text { Organização do lançamento da Frente Popular } \\
\text { dos Movimentos Sociais - PG }\end{array}$ & $\begin{array}{l}\text { Agosto de } 2016 \\
\text { (com ações de } \\
\text { comunicação em } \\
\text { continuidade) }\end{array}$ & $\begin{array}{l}\text { Frente Popular dos } \\
\text { Movimentos Sociais } \\
\text { - PG }(28 / 08 / 2015)\end{array}$ \\
\hline $\begin{array}{l}\text { Divulgação interna } \\
\text { e redes sociais }\end{array}$ & Ações de comunicação entre consumidores & $\begin{array}{l}\text { Setembro a atual } \\
(\text { em } \\
\text { continuidade })\end{array}$ & $\begin{array}{l}\text { Rede de Mulheres } \\
\text { Produtoras em } \\
\text { Agroecologia } \\
\text { Emiliano } \\
\text { Zapata/MST }\end{array}$ \\
\hline $\begin{array}{l}\text { Ações de divulgação } \\
\text { em redes sociais }\end{array}$ & 30 anos do Curso de Jornalismo da UEPG & Outubro/2015 & $\begin{array}{l}\text { Agência de } \\
\text { Jornalismo da UEPG }\end{array}$ \\
\hline $\begin{array}{l}\text { Comunicação em } \\
\text { redes sociais }\end{array}$ & $\begin{array}{l}\text { Manifesto contra o desastre em Bento } \\
\text { Rodrigues-Mariana/MG e morte do Rio Doce } \\
\text { pelos rejeitos da barragem de resíduos de } \\
\text { minérios da barragem Samarco/Vale - redes } \\
\text { sociais }\end{array}$ & Novembro/2015 & $\begin{array}{l}\text { Fórum das Águas } \\
\text { dos Campos Gerais }\end{array}$ \\
\hline $\begin{array}{l}\text { Release e divulgação } \\
\text { em redes socais }\end{array}$ & $\begin{array}{l}\text { Organização do lançamento da Frente Brasil } \\
\text { Popular Campos Gerais }\end{array}$ & $\begin{array}{l}\text { Dezembro/2015 } \\
\text { (ações de } \\
\text { comunicação em }\end{array}$ & $\begin{array}{l}\text { Frente Brasil } \\
\text { Popular Campos } \\
\text { Gerais }(16 / 12 / 2015)\end{array}$ \\
\hline
\end{tabular}




\begin{tabular}{|c|c|c|c|}
\hline & & continuidade) & \\
\hline $\begin{array}{l}\text { VT/TVCom e redes } \\
\text { sociais }\end{array}$ & I Conferência Municipal de Direitos Humanos & Fevereiro/2016 & $\begin{array}{l}\text { I Conferência } \\
\text { Municipal de } \\
\text { Direitos Humanos } \\
(13 / 02 / 2016)\end{array}$ \\
\hline $\begin{array}{l}\text { Release para } \\
\text { imprensa e } \\
\text { VT/TVCom }\end{array}$ & $\begin{array}{l}\text { Audiência Pública Reforma Agrária, } \\
\text { Agroecologia e Agricultura Camponesa }\end{array}$ & Fevereiro/2016 & $\begin{array}{l}\text { Pré-Assentamento } \\
\text { Maria Rosa/MST - } \\
\text { Castro (18/02/2016 }\end{array}$ \\
\hline $\begin{array}{l}\text { Atividades de } \\
\text { organização e } \\
\text { divulgação, } \\
\text { VT/TVCom e redes } \\
\text { sociais }\end{array}$ & $\begin{array}{l}\text { Painel "Desconstruir o Golpe, Defender a } \\
\text { Democracia" }\end{array}$ & Março/abril/2016 & $\begin{array}{l}\text { "Desconstruir o } \\
\text { Golpe, Defender a } \\
\text { Democracia" - } \\
\text { 31/03/2016 - } \\
\text { Agência de } \\
\text { Jornalismo e MsJor } \\
\text { UEPG }\end{array}$ \\
\hline $\begin{array}{l}\text { VT/TVCom e redes } \\
\text { sociais }\end{array}$ & $\begin{array}{l}\text { Campanha em defesa do saneamento básico } \\
\text { em Ponta Grossa }\end{array}$ & Março/2016 & $\begin{array}{l}\text { Caritas Diocesana } \\
\text { PG }\end{array}$ \\
\hline $\begin{array}{l}\text { VT/TVCom e redes } \\
\text { sociais }\end{array}$ & $\begin{array}{l}\text { Campanha em defesa do saneamento básico } \\
\text { em Ponta Grossa - resultado da CPI da } \\
\text { Sanepar }\end{array}$ & Março/2016 & $\begin{array}{l}\text { Fórum das Águas } \\
\text { dos Campos Gerais e } \\
\text { Caritas Diocesana } \\
\text { PG }\end{array}$ \\
\hline $\begin{array}{l}\text { VT/TVCom e redes } \\
\text { sociais }\end{array}$ & Ato em Defesa da Democracia & Abril/2016 & $\begin{array}{l}\text { Frente Popular dos } \\
\text { Movimentos Sociais } \\
\text { e Frente Brasil } \\
\text { Popular Campos } \\
\text { Gerais }(16 / 04 / 2016)\end{array}$ \\
\hline $\begin{array}{l}\text { Colaboração para } \\
\text { criação, implantação } \\
\text { e execução do } \\
\text { Programa }\end{array}$ & $\begin{array}{l}\text { "Democracia em Debate", veiculado na Rádio } \\
\text { Comunitária Princesa (FM 87,9), de segunda a } \\
\text { sexta-feira, das } 9 \text { h10 às } 930 \text { - redes sociais }\end{array}$ & Abril/2016 & $\begin{array}{l}\text { Rádio Comunitária } \\
\text { Princesa (FM 87,9), } \\
\text { Agência de } \\
\text { Jornalismo e MsJor }\end{array}$ \\
\hline $\begin{array}{l}\text { VT/TVCom e redes } \\
\text { socais }\end{array}$ & $\begin{array}{l}\text { Conferência } \\
26 / 04 / 2016\end{array}$ & Abril/2016 & $\begin{array}{l}\text { Agência de } \\
\text { Jornalismo }\end{array}$ \\
\hline $\begin{array}{l}\text { VT/TVCom e redes } \\
\text { sociais }\end{array}$ & $\begin{array}{l}\text { Chamada "Caminhada do Trabalhador" - para } \\
\left.\text { o Dia do Trabalho ( } 1^{\circ} \text { de maio }\right)\end{array}$ & Abril/2016 & $\begin{array}{l}\text { Pastoral Operária de } \\
\text { PG }\end{array}$ \\
\hline $\begin{array}{l}\text { Ações de } \\
\text { comunicação }\end{array}$ & Conferência das Cidades em PG & Abril/2016 & $\begin{array}{l}\text { Conferência das } \\
\text { Cidades em Ponta } \\
\text { Grossa }(13 \mathrm{e} \\
14 / 05 / 2016)\end{array}$ \\
\hline $\begin{array}{l}\text { Organização de } \\
\text { evento jornalístico }\end{array}$ & $\begin{array}{l}\text { Debate entre candidatos a prefeito de Ponta } \\
\text { Grossa - Eleições Municipais 2016, em } 23 \text { de } \\
\text { agosto de } 2016\end{array}$ & 23/agosto/2016 & $\begin{array}{l}\text { Mestrado em } \\
\text { Jornalismo e demais } \\
\text { PPG's da UEPG }\end{array}$ \\
\hline $\begin{array}{l}\text { Produção } \\
\text { audiovisual }\end{array}$ & $\begin{array}{l}\text { Marcha das mulheres camponesas no } 8 \text { de } \\
\text { Março (Dia Mundial da Luta das Mulheres) - } \\
\text { Ponta Grossa }\end{array}$ & $8 / \mathrm{março} / 2017$ & $\begin{array}{l}\text { Pré-Assentamento } \\
\text { Emiliano Zapata - } \\
\text { Ponta Grossa (MST) }\end{array}$ \\
\hline $\begin{array}{l}\text { Produção } \\
\text { audiovisual }\end{array}$ & $\begin{array}{l}\text { Lançamento oficial do documentário Doze } \\
\text { meses de resistência: a terra como horizonte }\end{array}$ & 9/julho/2017 & $\begin{array}{l}\text { Acampamento Maria } \\
\text { Rosa do Contestado }\end{array}$ \\
\hline
\end{tabular}




\begin{tabular}{|c|c|c|c|c|}
\hline & de vida. & & & (MST/Castro) \\
\hline $\begin{array}{l}\text { Ações de } \\
\text { comunicação interna } \\
\text { e externa e redes } \\
\text { sociais }\end{array}$ & $\begin{array}{l}\text { Rede de Mulheres } \\
\text { Agroecologia }\end{array}$ & Produtoras em & 2017-2018 & $\begin{array}{l}\text { Pré-Assentamento } \\
\text { Emiliano Zapata - } \\
\text { Ponta Grossa (MST) }\end{array}$ \\
\hline
\end{tabular}

Fonte: Agência de Jornalismo UEPG

As ações descritas neste artigo, voltadas a dar visibilidade para as entidades parceiras no espaço midiático local e regional, mostram as produções de caráter extensionista desenvolvidas pela Agência de Jornalismo, em sua totalidade, sem qualquer custo para as entidades parceiras, bem como sem recursos financeiros para o próprio programa.

\section{CONSIDERAÇÕES FINAIS}

O texto buscou apresentar um breve retrato do atual trabalho desenvolvimento pela Agência de Jornalismo UEPG, incluindo uma breve descrição contextual da realidade, indicando algumas das diferentes ações realizadas pelo programa extensionista ao longo de 15 anos de história. A atual ênfase de ação da Agência de Jornalismo da UEPG é nas atividades em parceria com as entidades e movimentos sociais parceiros.

O trabalho prescinde do interesse e esforços de professores e estudantes engajados em principais questões sociais, que demandam somar forças para o desenvolvimento de uma sociedade mais justa, democrática e inclusiva. Desta forma, a Agência de Jornalismo, programa de extensão que acumula expressiva atuação na cidade ao lado de setores sociais populares, por diversas razões e características regionais da instituição, também amplia as possibilidades de democratização da comunicação em Ponta Grossa, em que a produção e circulação da informação - como também ocorre em nível nacional, de modo geral - ainda se origina hegemonicamente de setores empresariais da mídia comercial privada.

Guardadas as proporções e limites, pode-se dizer que ocupar alguns espaços da grade de programação TV Comunitária e das redes sociais com informações provenientes dos setores sociais populares torna-se, neste aspecto, um desafio e serviço público imprescindível frente a uma demanda reprimida, conforme se constata no cotidiano das entidades e movimentos sociais parceiros da Agência de Jornalismo. 
i Uma versão prévia (como resumo expandido) do presente texto foi apresentado no $36^{\circ}$ Seminário de Extensão Universitária da Região Sul (SEURS36), realizado na Universidade Federal do Rio Grande do Sul, em Porto $\quad$ Alegre/RS, entre os dias 27 e 31 de agosto de 2018.

ii A previous version (as an expanded summary) of this text was presented at the 36th University Extension Seminar in the South Region (SEURS36), held at the Federal University of Rio Grande do Sul, in Porto Alegre / RS, between August 27 and 31 of 2018

\section{REFERÊNCIAS BIBLIOGRÁFICAS}

FRANÇA, C. G.; GROSSI, M. E.; MARQUES, V. P. M. A. El censo agropecuário de 2006 y la agricultura familiar en Brasil. Brasília, Unb. MDA, 2009. Disponível em http://www.repositorio.unb.br/bitstream/10482/14746/3/LIVRO_Censo\%202006\%20e

\section{\%20a\%20agricultura\%20familiar.pdf}

DE PAULA, J. A. “A extensão universitária: história, conceito e propostas”. In: Interfaces - Revista de Extensão, v. 1, n. 1, p. 05-23, jul./nov. 2013. Belo Horizonte: UFMG, 2013.

GADINI, S. L. "A TV Comunitária nos limites da fragilização da sociedade civil". In: Revista Emancipação. Ponta Grossa: UEPG, 2005. V. 5, N. 1. Disponível em http://www.revistas2.uepg.br/index.php/emancipacao/article/view/64

GADINI, S. L.; RIBEIRO, L. F.; ROCHA. P. M. "Projeto de Extensão e Mídia Comunitária: Reflexão sobre a parceria entre a Agência de Jornalismo UEPG e a TvComPG”. Trabalho apresentado no Seminário Regional de Extensão Universitária (SEURS). Porto Alegre/RS: UFRGS, 2012.

GONÇALVES, H.; RODRIGUES, A. C. L. “Atuação da Agência de Jornalismo em práticas comunicacionais para visibilidade de ações dos movimentos sociais populares". In: Conversando sobre Extensão (CONEX). Ponta Grossa: UEPG, Junho de 2017. Disponível http://www.uepg.br/proex/anais/11/

GONÇALVES, H. “Atuação da Agência de Jornalismo da UEPG em ações comunicacionais na parceria com entidades e movimentos sociais populares e TV Comunitária". Resumo expandido apresentado no Encontro Conversando sobre Extensão (CONEX). Ponta Grossa: UEPG, Junho de 2016. 
NOGUEIRA, M. D. P. (Org). Extensão Universitária Brasileira. Belo Horizonte: UFMPG/Fórum de Pró-Reitores de Extensão das Instituições Públicas de Educação Superior Brasileiras, 2013.

SIMÕES, C. F.; MATTOS, F. Elementos histórico-regulatórios da televisão brasileira. In: BOLAÑO, César. BRITTOS, Valério Cruz. Rede Globo: 40 anos de poder e hegemonia. São Paulo: Paulus, 2005. p. 35-55.

SILIPANDI, E. Mulheres e agroecologia. A construção de novos sujeitos políticos na agricultura familiar. Tese. Doutorado em Desenvolvimento Sustentável. Unb. $2009 . \quad$ Disponível em http://repositorio.unb.br/bitstream/10482/5591/1/2009_EmmaCademartoriSiliprandi.pdf

SZEREMETA, A.; ROCHA, P. M. "Agência de Jornalismo: 10 anos de extensão e produções comunicacionais". Resumo expandido apresentado no Conversando sobre Extensão (CONEX). Ponta Grossa: UEPG, 2013. Disponível em http://www.uepg.br/proex/anais/11/

WOITOWICZ, K. J.; CARMARGO, I. O.; GADINI, S. L. Experiências de apoio, diálogo e interação com movimentos sociais na Agência de Jornalismo da UEPG. Extensão em Foco. Curitiba: Ed. da UFPR, nr.9, jan/jun 2014, p.117-129. Disponível em https://www.researchgate.net/publication/287694145

WOITOWICZ, K. J.; GADINI, s. L.; FEOLLA, R. R.; KOSTER, G. R. “O papel da Agência de Jornalismo no apoio à produção de Crítica na TV”. Resumo expandido apresentado no $11^{\circ}$ CONEX. Ponta Grossa: UEPG, Junho de 2013. Disponível em http://www.uepg.br/proex/anais/11/

\section{MATERIAIS PRODUZIDOS PELA AGÊNCIA DE JORNALISMO} UEPG:

DOZE MESES DE RESISTÊNCIA. A terra como horizonte de vida. Agência de Jornalismo. Curso de Jornalismo. UEPG. 2017 (46 min.) Disponível em CD-Rom e redes sociais https://www.youtube.com/watch?v=6WcTMx4a-N4\&feature=share

15 Jornada de Agroecologia (MST). Lapa, 27 a 30 de julho de 2016. Conferência do teólogo Leonardo Boff. Agência de Jornalismo. UEPG. Disponível em 
https://www.youtube.com/watch?v=RRzI4gq7zPU e redes sociais e TV Com (canal 17, cabo)

14 Jornada de Agroecologia (MST). Irati. Julho de 2015. Conferência de João Pedro Stédile. Agência de Jornalismo. UEPG. Disponível em https://www.youtube.com/watch?v=eHRtnOFDrjc e redes sócias da Agência de Jornalismo e TVCom (canal 17, cabo).

Ato contra o desmonte da Previdência Social - Agência de Jornalismo. UEPG, 31 de março de 2017. Disponível em https://www.youtube.com/watch?v=6zfbWN2I9GM e redes sócias da Agência de Jornalismo e do Fórum em Defesa da Previdência Social e na TVCom (canal 17, cabo)

Camponesas na Marcha Mundial das Mulheres. Agência de Jornalismo. UEPG, 8 de março de 2017. Disponível em https://www.youtube.com/watch?v=ghxIfgQh9ds e redes sociais da Agência de Jornalismo e demais movimentos sociais e TV Com (canal 17, cabo)

CPI Sanepar. Produção para Fórum das Águas dos Campos Gerais. Agência de Jornalismo. Março de 2016. Disponível em https://www.youtube.com/watch?v=Yiud4HjNLTE

Debate entre os candidatos a prefeito de Ponta Grossa. Eleições 2016. 23 de agosto de 2016. Agência de Jornalismo. Disponível em https://www.youtube.com/watch?v=1dRO1d4kOFM e redes sociais da Agência de Jornalismo.

Procissão do Dia do Trabalhador. $1^{\circ}$ de maio de 2016. Agência de Jornalismo. Disponível em https://www.youtube.com/watch?v=Y2S_VW32-Jg e redes sociais da Agência de Jornalismo e TVCom (Canal 17, cabo).

Produção de divulgação da TVCom. Agência de Jornalismo. Julho 2016. Disponível em https://www.youtube.com/watch?v=IrWMd4ZwR_o e TVCom (Canal 17, cabo).

\section{Alimentação da página da Rede de Mulheres Produtoras em Agroecologia} https://www.facebook.com/Rede-de-Mulheres-Produtoras-em-Agroecologia-122739208384946/

\section{DOCUMENTO}


MANIFESTO DE CORDOBA. Reforma de Cordoba. Conferências UFRGS. CRES 2018. Disponível em https://www.ufrgs.br/cres2018ufrgs/reforma-de-cordoba/ Acesso em 30/08/2019.

UNIÃO NACIONAL DOS ESTUDANTES (UNE). História da UNE. Disponível em https://une.org.br/2011/09/historia-da-une/ Acesso em 30/08/2019.

Recebido em: 27 de novembro de 2019. Aceito em: 14 de julho de 2020. 